\title{
PERILAKU KEAGAMAAN DAN HASIL BELAJAR PENDIDIKAN AGAMA ISLAM DI SMA NEGERI 1 AMBARAWA KABUPATEN PRINGSEWU
}

\author{
Rahmat Efendi \\ STIKES Muhamadiyah Pringsewu \\ Jl. Makam H. Gholib Pringsewu
}

\begin{abstract}
Religious behavior student become a benchmark for the success of learning, especially learning Islam. Where the results of learning Islamic education not only from the aspect of cognitive but also affective and psychomotor aspects.

Therefore, it is very interesting to do research if there is a relationship between religious behavior with Islamic education learning outcomes. The purpose of this study was to determine whether or not the relationship of religious behavior with Islamic education learning outcomes. The method used in this research is descriptive analysis method with quantitative research forms. The results showed no relationship between religious behavior with Islamic education learning outcomes. This conclusion is based on the correlation test was done using the formula Kendal tau test with SPSS. The test results show significant figures $0548>0.05$. Shown significant values greater than 0.05 means that there is a relationship between religious behavior of students with the learning outcomes of Islamic Education in SMA Negeri 1 Ambarawa Pringsewu.
\end{abstract}

Abstrak

Perilaku keagamaan siswa menjadi tolak ukur keberhasilan sebuah pembelajaran, khususnya pembelajaran Agama Islam. Dimana hasil belajar Pendidikan Agama Islam bukan hanya dilihat dari aspek kognitif saja namun juga aspek afektif dan psikomotorik. Oleh karena itu, sangat menarik untuk dilakukan penelitian apakah ada hubungan antara perilaku keagamaan dengan hasil belajar Pendidikan Agama Islam. Tujuan dari penelitian ini adalah untuk mengetahui ada atau tidaknya hubungan perilaku keagamaan dengan hasil belajar Pendidikan Agama Islam. Metode yang digunakan dalam penelitian ini adalah metode deskriptif analisis dengan bentuk penelitian kuantitatif.

Hasil penelitian menunjukan ada hubungan antara perilaku keagamaan dengan hasil belajar Pendidikan Agama Islam. Kesimpulan ini berdasarkan uji korelasi yang telah dilakukan menggunakan rumus uji kendal tau dengan bantuan program SPSS. Adapun hasil pengujian menunjukan angka signifikan $0.548>0,05$. Nilai signifikan yang ditunjukan lebih besar dari 0,05 berarti ada hubungan antara perilaku keagamaan siswa dengan hasil belajar Pendidikan Agama Islam di SMA Negeri 1 Ambarawa Pringsewu.

Kata Kunci: Perilaku keagamaan, Hasil Belajar PAI. 


\section{A. PENDAhuluan}

Hakekat pendidikan adalah usaha sadar untuk menumbuh kembangkan potensi sumber daya manusia melalui kegiatan pengajaran (Muhibbin Syah, 1997:1). Menurut Poerbakawatja dan Harahap sebagaimana dikutip Muhibbin Syah (1997: 11), pendidikan diartikan sebagai usaha secara sengaja dari orang dewasa dengan pengaruhnya untuk meningkatkan anak ke arah kedewasaan yang selalu diartikan mampu menimbulkan tanggungjawab moril dari segala perbuatannya. Orang dewasa itu adalah orang tua anak atau orang yang atas dasar tugas dan kedudukannya mempunyai tugas untuk mendidik.

Pendidikan dalam realisasinya dapat berlangsung secara formal (sekolah), nonformal (masyarakat) dan informal (keluarga) (Abu Ahmadi,1991:191). Dari ketiga jalur pendidikan tersebut, pendidikan informal atau pendidikan yang berlangsung dalam keluarga menempati peranan yang sangat penting, karena keluarga merupakan lembaga sosial pertama bagi setiap anak untuk mengembangkan dirinya.

Dalam Undang-Undang RI No. 20 Tahun 2003 dinyatakan bahwa "pendidikan keluarga merupakan bagian dari jalur pendidikan luar sekolah yang diselenggarakan dalam keluarga dan yang memberikan keyakinan agama, nilai budaya, nilai moral dan ketrampilan" (UU RI NO 20 Tahun 2003;6). Dengan demikian, esensi pendidikan merupakan proses menghadirkan situasi dan kondisi yang memungkinkan sebanyak mungkin subjek didik memperluas dan memperdalam makna-makna esensial untuk mencapai kehidupan manusiawi. Sehingga sangat diperlukan adanya kesengajaan atau kesadaran (niat) untuk mengundangnya melakukan tindak belajar.

Secara umum belajar dikatakan sebagai proses interaksi antara diri manusia dengan lingkungannya yang mungkin berwujud pribadi, fakta konsep ataupun teori (Moh Shokib, 1998:3).Oleh karena itu belajar juga dapat berarti suatu kegiatan yang berproses dan unsur yang sangat fundamental dalam setiap jenis dan jenjang pendidikan.

Hal ini berarti bahwa berhasil atau gagalnya pencapaian tujuan pendidikan sangat bergantung pada proses belajar yang dialami siswa baik ketika siswa berada di sekolah maupun di lingkungan rumah atau keluarganya. Oleh karena itu diperlukan suatu pemahaman yang besar mengenai arti belajar dengan segala aspek, bentuk dan manifestasinya secara mutlak. Kekeliruan atau ketidak lengkapan persepsi terhadap proses belajar dan hal-hal yang berkaitan dengannya mungkin akan mengakibatkan kurang bermutunya hasil pembelajaran yang dicapai anak.

Sebagaimana diketahui bahwa belajar adalah merupakan aktivitas yang sangat kompleks maka banyak sekali faktorfaktor yang mempengaruhinya. Secara global faktor-faktor tersebut adalah pertama faktor internal siswa, yakni kondisi dalam diri siswa yang meliputi aspek fisiologis dan psikologis, kedua faktor eksternal siswa, yakni kondisi lingkungan sekitar siswa yang me liputi lingkungan sosial dan non-sosial (Suryabrata, 1998:133).
Pendidikan Islam harus mempunyai karakter sebagai lembaga pendidikan yang menghidupkan sistem demokrasi dalam pendidikan. Sistem pendidikan yang memberikan keleluasaan pada peserta didik untuk mengekspresikan pendapatnya secara bertanggungjawab. Sekolah memfasilitasi adanya "mimbar bebas", dengan memberikan kesempatan kepada semua civitas untuk berbicara atau mengkritik tentang apa saja, asal bertanggungjawab. Tentunya, sistem demokrasi ini akan memberikan pendidikan pada peserta didik tentang realitas sosial yang mempunyai pandangan dan pendapat yang berbeda.

Dalam tujuan umum pendidikan Islam dekemukakan bahwa, tujuan pendidikan Islam adalah membina peserta didik agar menjadi hamba yag suka beribadah kepada Allah, ibadah disini tidak hanya terbatas pada menunaikan shalat, puasa di bulan Ramadhan,mengeluarkan zakat dan beribadah haji, setelah mengucapkan syahadat tauhid dan syahadat Rasul. Tetapi mencakup segala amal, pikiran atau perasaan manusia selama semua itu dihadapkan kepada Allah SWT (Nur Uhbiyati, 1997:43).

Pendidikan dapat diartikan sebagai sebuah proses dengan metode- metode tertentu sehingga peserta didik memperoleh pengetahuan, pemahaman, dan cara bertingkah laku yang sesuai dengan kebutuhan. Pendidikan merupakan sarana untuk menyiapkan generasi masa kini dan sekaligus masa depan. Hal ini berarti bahwa proses pendidikan yang dilakukan pada saat ini bukan semata-mata untuk hari ini, melainkan untuk masa depan.

Selain itu pendidikan juga merupakan suatu upaya untuk meningkatkan kualitas SDM baik fisik, mental maupun spiritual. Sejalan dengan konsep pendidikan yang dicanangkan oleh PBB bahwa pendidikan ditegakkan oleh 4 pilar, yaitu learn to know, learn to do, learn to live together dan learn to $b e$. Pilar pertama dan kedua lebih diarahkan untuk membentuk sense of having yaitu bagaimana pendidikan dapat mendorong terciptanya sumber daya manusia yang memiliki kualitas di bidang ilmu pengetahuan dan ketrampilan agar dapat digunakan untuk meningkatkan kualitas hidup, sehingga mendorong sikap proaktif, kreatif dan inovatif ditengah kehidupan masyarakat. Sementara pilar ketiga dan keempat diarahkan untuk membentuk karakter bangsa atau sense of being, yaitu bagaimana harus terus menerus belajar, dan membentukan karakter yang memiliki integritas dan tanggung jawab serta memiliki komitmen untuk melayani sesama. Sense of being ini penting karena sikap dan perilaku seperti ini akan mendidik peserta didik untuk belajar saling memberi dan menerima serta belajar untuk menghargai serta menghormati perbedaan atas dasar kesetaraan dan toleransi ( Pupuh F, 2007: 5-8).

Pengertian pendidikan sebagaimana tercantum dalam undang-undang no 20 tahun 2003 tentang sistem pendidikan nasional adalah suatu usaha sadar dan terencana untuk mewujudkan suasana belajar dan proses pembelajaran agar peserta didik secara aktif mengembangkan potensi dirinya untuk memiliki kekuatan spiritual keagamaan, pengendalian diri, kepribadian, kecerdasan, akhlak mulia serta keterampilan yang diperlukan dirinya, masyarakat, bangsa dan Negara (Abdurrahman Sholeh, 2005:2).

Pendidikan agama merupakan bagian terpenting yang harus dilaksanakan dalam rangka meningkatkan keimanan dan 
ketaqwaan peserta didik untuk menjadi manusia yang berakhlak mulia (bermoral). Sebab dewasa ini bangsa Indonesia sedang mengalami krisis yang berkepanjangan, terutama krisis moral. Memiliki ilmu yang tinggi tanpa dibarengi dengan keimanan dan ketaqwaan dapat membahayakan dan merusak tatanan hidup umat manusia itu sendiri, karena akan melahirkan manusia-manusia yang rakus yang hanya mementingkan diri sendiri tanpa mempedulikan kepentingan umum.

Pendidikan agama Islam diartikan sebagai usaha sadar untuk menyiapkan peserta didik dalam meyakini, memahami, menghayati, dan mengamalkan agama Islam melalui kegiatan, bimbingan, pengajaran dan atau latihan (Shaleh, 2000:40). Adapun tujuan pelaksanaan pembelajaran Pendidikan Agama Islam di sekolah adalah untuk menumbuhkan dan meningkatkan keimanan dan ketaqwaan kepada Allah SWT., serta pengamalan peserta didik tentang agama Islam sehingga menjadi manusia muslim yang terus berkembang dalam hal keimanan dan ketaqwaannya kepada Allah SWT. Serta berakhlak mulia dalam kehidupan pribadi, bermasyarakat, berbangsa dan bernegara (Kurikulum Berbasis Kompetensi, tt :238).

Dengan demikian pelaksanaan kurikulum Pendidikan Agama di sekolah diharapkan mampu menghasilkan peserta didik yang benar-benar memiliki keimanan yang kuat dan ketaqwaan yang tinggi dengan dilandasi oleh akhlak mulia sehingga dapat diimplementasikan dalam kehidupan seharihari. Sedangkan rujukan tujuan pendidikan yang dilaksanakan di Indonesia secara umum terdapat dalam Undang-undang Nomor 20 tahun 2003 Bab II pasal 3 tentang Sistem Pendidikan Nasional, menyatakan bahwa tujuan pendidikan Nasional adalah:

"Untuk berkembangnya potensi peserta didik agar menjadi manusia yang beriman dan bertaqwa kepada Tuhan Yang Maha Esa, berakhlak mulia, sehat, berilmu, cakap, kreatif, mandiri dan menjadi warga negara yang demokratis serta bertanggung jawab" (UU RI 2003: 9) Namun demikian fenomena yang terjadi walaupun tidak semuanya pada anak didik sekarang ini, munculnya kenakalan remaja, seperti tawuran antar pelajar, keterlibatan dalam pencurian, serta adanya berita tertangkapnya siswa mabuk-mabukan.

Dalam lingkup kenakalan yang lebih kecil siswa membolos, berkata yang tidak sesuai dengan ajaran agama atau etika, bahkan sering kita dengar tiap hari anak-anak dengan enaknya berkata-kata jorok tidak sopan. Demikian juga dengan sikap mereka terhadap orang yang lebih tua, tidak mengindahkan etika dan sopan santun. Padahal kita ketahui hasil belajar mereka bagus, mendapatkan nilai setiap mata pelajaran dengan nilai yang memuaskan melebihi KKM yang telah ditentukan.

Berkaitan dengan hal tersebut perubahan-perubahan yang terjadi begitu cepat dan dahsyat dalam berbagai bidang kehidupan manusia dewasa ini, baik dalam bidang ekonomi, politik, sosial, budaya, pendidikan, pertahanan dan keamanan sebagai dampak dari kemajuan ilmu pengetahuan dan teknologi telah melahirkan globalisasi informasi yang bebas nilai telah turut menggeser nilai-nilai luhur kehidupan sosial umat manusia kearah gaya hidup individualism, materialism, pragmatism dan hedonism (Rahim, 2001: 37).
Krisis moral (moral crisis) yang terjadi saat ini menurut H.A.R. Tilaar bukan hanya dirasakan oleh bangsa dan masyarakat Indonesia saja, tetapi juga oleh Negara-negara maju, seperti Amerika dan Negara industri maju lainnya dan nampaknya sudah menjadi masalah global. Menanggapi masalah dekadensi moral tersebut, kini pendidikan di seluruh dunia menyadari dan sedang mengkaji akan pentingnya pendidikan nilai-nilai moral di sekolah (Tilaar, 1999: 74).

Sementara itu, dalam perspektif hukum (perundangundangan), terkait dengan peran strategis Pendidikan Agama, dalam Undang-Undang Sistem Pendidikan Nasional Nomor 20 Tahun 2003 pada bab IX tentang kurikulum pada pasal 37 disebutkan bahwa kurikulum pendidikan dari pendidikan dasar sampai pendidikan tinggi wajib memuat Pendidikan Agama. Selanjutnya dalam penjelasan mengenai pasal 37 ayat (1) dijelaskan bahwa Pendidikan Agama bertujuan membentuk peserta didik menjadi manusia beriman kepada Tuhan Yang Maha Esa serta berakhlak mulia (Penyusun, 2006: 19 dan 50).

Kalau kita melihat dari aspek pendidikan, sebagai bagian dari sub-sistem pendidikan nasional, Pendidikan Agama menempati bagian dasar dalam usaha pendidikan nasional, terutama dalam mengantisipasi krisis moral/akhlak (moral crisis) yang kini tampak semakin menggejala dalam kehidupan masyarakat, yang menjadi pangkal utama penyebab timbulnya krisis multidimensional, dimana diduga kuat sebagai salah satu faktor penyebabnya adalah gagalnya pelaksanaan Pendidik Agama Islam di sekolah umum dalam membentuk moralitas bangsa secara umum dan moralitas peserta didik secara khusus (Azizy, 2003: 60).

Pembelajaran Pendidikan Agama Islam di SMA Negeri 1 Ambarawa yang berjalan selama ini diduga belum begitu berhasil mencapai tujuan yakni membentuk perilaku religius, mengapa? Karena berdasarkan studi pendahuluan berupa wawancara dan observasi sementara penulis dengan Kepala Sekolah hipotesa tersebut didukung dengan beberapa indikasi; antara lain adanya kasus siswa yang tidak melakukan shalat lima waktu secara lengkap, tidak berpuasa penuh pada bulan Ramadhan, dan indikasi lainnya.

Salah satu tujuan pemberian mata pelajaran Agama Islam antara lain untuk membentuk perilaku religius. Oleh karena itu, penilaian proses hasil belajar mata pelajaran Pendidikan Agama Islam seyogyanya memiliki relevansi dengan kualitas perilaku keislamannya sehari-hari. Guna mewujudkan perilaku religius tersebut, banyak faktor yang turut mempengaruhi.

Faktor-faktor yang mempengaruhi perilaku keagamaan dalam kehidupan sehari-hari, baik di rumah tangga, sekolah maupun di lingkungan masyarakat berbagai perilaku dapat ditunjukkan oleh masing-masing individu, termasuk perilaku keagamaan yang ditunjukkan para siswa. Perilaku keagamaan masing-masing siswa tidak selamanya berlangsung dengan baik dan juga tidak semua siswa menunjukkan perilaku religius. Hal ini disebabkan karena proses pembentukan dan perubahan perilaku keagamaan dipengaruhi oleh berbagai faktor, baik yang berasal dari dalam diri maupun yang berasal dari luar dirinya.

Faktor dari dalam (internal) meliputi antara lain; pengetahuan, sikap, tindakan (praktik), kesadaran diri pribadi (motivasi) siswa itu sendiri, termasuk faktor pengalaman keagamaan. Sedangkan faktor dari luar individu (eksternal) 
seperti faktor orang tua (keluarga), guru, lingkungan masyarakat sekitarnya, termasuk teman-temannya.

Atas dasar pemikiran di atas, untuk mengetahui lebih jauh mengenai hubungan antara perilaku keagamaan siswa dengan hasil belajar Pendidikan Agama Islam, menurut penulis perlu untuk diteliti lebih lanjut dalam sebuah penelitian dengan judul Hubungan Antara Perilaku Keagamaan Siswa Dengan Hasil Belajar Pendidikan Agama Islam di SMA Negeri 1 Ambarawa Kabupaten Pringsewu

Dari paparan di atas nampaklah bahwa eksistensi dan signifikansi Pendidikan Agama Islam sangat dibutuhkan oleh masyarakat Indonesia untuk membentuk manusia yang beriman dan bertakwa kepada Tuhan Yang Maha Esa serta berakhlak mulia dalam menjalankan kehidupan khususnya di tengah arus informasi dan globlalisasi seperti yang terjadi sekarang ini.

\section{B. TUJUAN PENELITIAN}

Tujuan dari penelitian ini adalah untuk mengetahui ada atau tidaknya hubungan perilaku keagamaan dengan hasil belajar Pendidikan Agama Islam.

\section{METODE PENELITIAN}

Berdasarkan pendekatannya, maka penelitian ini termasuk penelitian kuantitatif. Penelitian kuantitatif didasari oleh filsafat positivisme yang menekankan fenomena-fenomena objektif dan dikaji secara kuantitatif. Maksimalisasi objektivitas desain penelitian ini dilakukan dengan menggunakan angka-angka, pengolahan statistik, struktur dan percobaan terkontrol.

Berdasarkan pendeskripsian diatas, motode yang digunakan adalah metode survei untuk memperoleh gambaran hubungan perilaku keagamaan dengan hasil belajar pendidikan agama Islam di SMA Negeri 1 Ambarawa Pringsewu. Adapun teknik analisis data tentang hubungan variabel data menggunakan alat statistik inferensial, korelasi sederhana dan korelasi ganda, korelasi parsial, serta regresi berganda.

Populasi yang akan dipilih oleh peneliti adalah seluruh siswa kelas XII SMA Negeri 1 Ambarawa tahun pelajaran 2013/2014 dengan perincian jurusan IPA sejumlah 3 kelas dan jurusan IPS sejumlah 4 kelas dengan jumlah keseluruhan 241 siswa. Teknik pengambilan sampel menggunakan purpose sampling

\section{HASIL DAN PEMBAHASAN}

Deskripsi data merupakan kategorisasi dan peringkasan data untuk memperoleh jawaban bagi pertanyaan penelitian. Secara singkat deskripsi data menyangkut nilai rata-rata (mean), median, mode, standar deviasi, variance, skewness, kurtosis, skor minimum dan skor maksimum yang secara empiris diperoleh responden, sehingga akan tampak rentang datanya. Adapun data hasil penelitian masing-masing variabel adalah sebagai berikut:

1. Variabel Perilaku Keagamaan Siswa (X)

Dapat dijelaskan sebagai berikut: $\mathrm{N}$ atau jumlah data valid di proses adalah 151. Mean atau nilai rata-rata adalah 45,74. Median atau titik tengah data adalah 46,00. Median dapat diartikan bahwa 50\% data berada di atas 46,00 dan sisanya berada di bawahnya. Mode merupakan nilai yang paling banyak muncul yaitu 46. Standar deviasi dan variansi digunakan untuk menilai tingkat sebaran data. Pada tingkat kepercayaan 95\% kita gunakan 2 kali standar deviasi sehingga Mean \pm 2 standar deviasi $=45,74 \pm(2 \mathrm{x}$ $5,566)=45,75 \pm(11,132)=34,618$ sampai 56,882 . Perhatikan bahwa nilai minimum (28) dan nilai maksimum (59) beda tipis dengan interval kepercayaan 95\% sehingga dapat dikatakan bahwa data di atas adalah baik.

Ukuran kepencongan (skewness) sebesar -0,191 dengan standar error 0,197 .

Rasio skewness $=-\underline{0,191}=-0,969$

$$
0,197
$$

Sebagai pedoman jika rasio skewness berada di antara -2 dan 2 maka distribusi data tersebut adalah normal. Ukuran kepuncakan (kurtosis) sebesar 0,178 dengan standar error 0,392

Rasio kurtosis $=\frac{-0,178}{0,392}=-0,454$

Sebagai pedoman, jika rasio kurtosis berada di antara -2 dan 2 maka distribusi data tersebut adalah normal. Data minimum adalah 28 dan data maksimum adalah 59 dengan range $=31$.

\section{Variabel Hasil Belajar Pendidikan Agama Islam (Y)}

Dapat dijelaskan sebagai berikut: $\mathrm{N}$ atau jumlah data valid di proses adalah 151. Mean atau nilai rata-rata adalah 79,14. Median atau titik tengah data adalah 79,00. Median dapat diartikan bahwa $50 \%$ data berada di atas 79,00 dan sisanya berada di bawahnya. Mode merupakan nilai yang paling banyak muncul yaitu 80. Standar deviasi dan variansi digunakan untuk menilai tingkat sebaran data. Pada tingkat kepercayaan 95\% kita gunakan 2 kali standar deviasi sehingga Mean \pm 2 standar deviasi $=79,14 \pm(2 \times 2,419)=79,14 \pm$ $(4,838)=74,302$ sampai 83,978. Perhatikan bahwa nilai minimum (75) dan nilai maksimum (90) beda tipis dengan interval kepercayaan 95\% sehingga dapat dikatakan bahwa data di atas adalah baik.

Ukuran kepencongan (skewness) sebesar 1,630 dengan standar error 0,197.

Rasio skewness $=\underline{1,630}=8,274$

$$
0,197
$$

Sebagai pedoman jika rasio skewness berada di antara -2 dan 2 maka distribusi data tersebut adalah normal. Ukuran kepuncakan (kurtosis) sebesar 3,751 dengan standar error 0,392

Rasio kurtosis $=\underline{3,751}=9,569$

$$
0,392
$$

Sebagai pedoman, jika rasio kurtosis berada di antara -2 dan 2 maka distribusi data tersebut adalah normal. Data minimum adalah 75 dan data maksimum adalah 90 dengan range $=15$.

\section{E. PENUTUP}

\section{1). Kesimpulan}

Berdasarkan hasil temuan penelitian yang telah dikemukakan sebelumnya mengenai hubungan antara perilaku keagamaan siswa dengan hasil belajar Pendidikan Agama Islam, dapatlah diambil beberapa kesimpulan bahwa ada hubungan antara perilaku keagamaan siswa dengan hasil belajar Pendidikan Agama Islam. Kesimpulan ini berdasarkan 
uji korelasi yang telah dilakukan menggunakan rumus uji tau kendal dengan bantuan program SPSS. Adapun hasil pengujian menunjukan angka signifikan $0.548>0,05$. Nilai signifikan yang ditunjukan lebih besar dari 0,05 ada hubungan antara perilaku keagamaan siswa dengan hasil belajar Pendidikan Agama Islam di SMA Negeri 1 Ambarawa Pringsewu.

\section{2). Saran}

Guru diharapkan dapat terus menanamkan perilaku keagamaan kepada siswa untuk setiap mata pelajaran. Siswa diharapkan untuk selalu mengerjakan hal-hal yang positif dan terus memiliki perilaku keagamaan yang meningkat dari hari sebelumnya.

\section{DAFTAR PUSTAKA}

Abu Ahmadi dan Nur Uhbiyati 2001, Ilmu Pendidikan, Jakarta: PT. Rineka Cipta.

Azizy, A Qodri.2003. Pendidikan Untuk Membangun EtikaSosial, Semarang: Aneka Ilmu.

H.A.R. Tilaar.1999. Manajemen Pendidikan Nasional. PT Remaja. Rosdakarya

Rahim, Husni, Arah Baru Pendidikan Islam di Indonesia, Jakarta : Logos Wacana Ilmu, 2001.

Saleh, Abdurrochman.2005. Pedoman Pembinan Pondok Pesantren. Jakarta: Proyek Pembinaan Bantuan Kepada Pondok Pesantren Ditjen Binbaga Islam Depag RI.

Syah Muhibbin,. 2006. Psikologi Belajar, Jakarta: PT. Raja Grapindo Persada.

UU RI no 20 Tahun 2003 Sistem Pendidikan Nasional 